\title{
FINTECH SYARIAH DALAM PERSPEKTIF HUKUM ISLAM
}

\author{
Evan Hamzah Muchtar \\ STAI Asy-Syukriyyah Tangerang \\ evan.hamzah.m@gmail.com \\ Ahmad Zubairin \\ STAI Asy-Syukriyyah Tangerang \\ alzuber82@gmail.com
}

\begin{abstract}
This study aims to determine Islamic fintech in the perspective of Islamic law with a qualitative descriptive method. The type of research used in this study is a literature study obtained from various sources. The results obtained indicate that Sharia fintech is a discussion of contemporary fiqh that has not been decided in the Qur'an and the Hadith of the Prophet SAW, thus using ijma (ulama consensus) as a source of law. The Indonesian Ulema Council issued the Fatwa of the National Sharia Council-Indonesian Ulema Council (DSN-MUI) No. 117/DSN-MUI/II/2018 concerning Information Technology-Based Financing Services Based on Sharia Principles. The fatwa is in accordance with Islamic law and has clear legal protection and is contained in the legislation.
\end{abstract}

Keywords: Islamic Fintech, Islamic Law

\section{PENDAHULUAN}

Dalam semua kegiatan ekonomi, teknologi digital merupakan terobosan dan inovasi baru. Hal ini berpotensi berdampak pada industri perdagangan, pertanian, dan, terutama, sektor keuangan. Financial Technology atau lebih sering dikenal dengan Fintech merupakan salah satu industri yang kini sedang berkembang. Fintech merupakan inovasi terbaru saat ini. Teknologi keuangan adalah perusahaan layanan pembiayaan berbasis syariah dan teknologi informasi. Fintech mendapatkan daya tarik di seluruh dunia sebagai teknologi yang memungkinkan bisnis bersaing lebih sukses di abad kedua puluh satu. Pemerintah di seluruh dunia telah memperhatikan masalah dan mengembangkan undang-undang dan peraturan untuk mempromosikan pengembangan Fintech. Fintech (financial technology) merupakan peluang pasar yang sangat menjanjikan di Indonesia. Wilayah Indonesia yang sangat luas, Ada banyak pertumbuhan kelas menengah yang terjadi, tetapi potensi produk keuangannya tidak besar. 
Perkembangan fintech menjadi pasar yang tangguh. Fintech di Indonesia menjanjikan layanan keuangan yang dapat diakses oleh masyarakat unbanked, dengan hanya $36 \%$ dari populasi yang memiliki rekening bank.

Hingga akhir 2020, nilai pinjaman fintech syariah mencapai Rp 1,7 triliun, naik dari realisasi tahun sebelumnya $\mathrm{Rp} 1$ triliun. Saat itu, jumlah pemain fintech syariah baik yang terdaftar maupun berizin berjumlah 10 platform (www.kontan.com). Berdasarkan data Statistik Fintech Lending periode Mei 2021 (Otoritas Jasa Keuangan, 2021) total assets penyelenggara fintech Syariah sebesar Rp121 miliar, total liabilitas sebesar Rp76 miliar dan total ekuitas sebesar Rp45 miliar.

Penerapan Fintech dalam fiqh muamalah harus didasarkan pada prinsip-prinsip syariah, seperti menghindari Maysir, Gharar, dan Riba, agar dapat mengikuti perkembangannya saat ini. Penelitian sebelumnya yang dilakukan oleh Aziz menyatakan ${ }^{1}$ Sebelum melihat fungsinya, kemajuan teknologi tidak dapat mendukung syariahnya. Lebih lanjut beliau menyatakan Hukum Fintech cukup bervariasi dalam hal manfaat dan kontra dari prosesnya.

Berdasarkan uraian diatas penulis berpendapat kegiatan transaksi muamalah yang menggunakan sistem teknologi harus tetap berpedoman pada prinsip-prinsip hukum Islam. Oleh karena itu penelitian terhadap fintech dengan pendekatan perspektif hukum Islam ini menarik dilakukan agar umat Islam dapat mengikuti kemajuan teknologi dan lembaga keuangan Fintech dengan tetap berpegang pada jalur syariah.

\section{METODE PENELITIAN}

Metodologi deskriptif kualitatif digunakan dalam penelitian ini. Metode penelitian yang dipilih adalah penelitian kepustakaan. Informasi yang dikumpulkan adalah narasi deskriptif mengenai Fintech Syariah dalam Prespektif Hukum Islam. Sebagai penelitian library research, dokumentasi adalah cara yang digunakan untuk memperoleh data, dengan mengambil data yang berasal dari berbagai literatur yang relevan, terutama pada Fatwa MUI Nomor: 117/DSNMUI/II/2018 tentang Layanan Pembiayaan Berbasis Teknologi Informasi Berdasarkan Prinsip Syariah. Dapat dijadikan dasar dalam menentukan hukum Fintech dalam islam yang menjadi literatur pokok dalam pembahasan, untuk kemudian data ini diinterpretasikan menjadi narasi kritis terhadap judul yang dibahas dalam penelitian.

\footnotetext{
${ }^{1}$ Fathul Aminudin Aziz, "Menakar Kesyariahan Fintech Syariah Di Indonesia," Al-Manahij: Jurnal Kajian Hukum Islam 14, no. 1 (2020): 1-18.
} 


\section{HASIL PENELITIAN DAN PEMBAHASAN}

\section{Sekilas Mengenai Fintech Syariah}

Menurut PWC, teknologi keuangan adalah segmen yang dinamis di persimpangan layanan keuangan dan industri teknologi, di mana perusahaan rintisan pendatang pasar baru dan berfokus pada teknologi merevolusi barang dan jasa industri jasa keuangan tradisional. Arti lain dari fintech adalah penggunaan teknologi untuk menciptakan solusi sektor keuangan. ${ }^{2}$

Pengertian Fintech Syariah menurut Fatwa DSN-MUI penyediaan jasa keuangan syariah yang mempertemukan atau menghubungkan pemodal dan penerima dana dalam rangka mengadakan akad pembiayaan melalui sistem elektronik dengan memanfaatkan jaringan internet.

\section{Perkembangan Fintech Syariah}

Hadirnya Fintech (financial technology) merupakan terobosan baru yang menunjukkan pertumbuhan teknologi berbasis digital, yang berdampak pada seluruh operasional perekonomian, telah menjadi ciri perkembangan teknologi. Fintech adalah perusahaan yang mengkhususkan diri dalam menyediakan layanan keuangan melalui penggunaan perangkat lunak dan teknologi mutakhir. Lebih lanjut, gagasan yang menunjukkan bagaimana para ekonom membawa fintech, Joseph Schumpeter dengan tesisnya tentang penghancuran kreatif, yang menyatakan bahwa penemuan baru memiliki efek membunuh pemain lama dan menggantinya dengan sesuatu yang baru. Namun gagasan ini belum mampu menjelaskan secara utuh dampak dari terobosan baru berupa fintech. Alasannya, tujuan fintech bukan untuk menghilangkan petahana lama. Fintech, di sisi lain, secara bertahap menggantikan fungsi incumbent dengan sesuatu yang lebih baik, lebih cepat, dan lebih murah. ${ }^{3}$ Selanjutnya, tujuan fintech harus selaras dengan tujuan transaksi, yaitu menghasilkan dan memelihara manfaat (kebaikan) sekaligus menghindari bahaya (kerusakan) di dunia dan akhirat. ${ }^{4}$

Evolusi fintech tradisional disejajarkan dengan evolusi fintech syariah. Tentu saja ada perbedaan antara fintech Islam dan tradisional. Karena tentunya Akseptasi transaksi yang telah selesai harus sesuai dengan ketentuan syariah, baik dari segi rukun maupun syarat akad. Fintech

\footnotetext{
${ }^{2}$ Rohmatun Nafiah and Ahmad Faih, “Analisis Transaksi Financial Technology (Fintech) Syariah Dalam Perspektif Maqashid Syariah,” IQTISHADIA: Jurnal Ekonomi Dan Perbankan Syariah 6, no. 2 (2019): 167-75.

${ }^{3}$ Renald Kasali, Discruption (Jakarta: Gramedia Pustaka Utama, 2017).

${ }^{4}$ Shidik., Ushul Figh. (Jakarta: PT. Intimedia Cipta Nusantara, 2016).
} 
syariah muncul sebagai respons terhadap kemajuan teknologi, yang menunjukkan bahwa perilaku manusia juga berubah.

Berdasarkan data Databoks (2017), transaksi financial technology (fintech) PDB Indonesia diperkirakan akan mencapai US\$ 18,65 miliar pada tahun 2017. Pada tahun 2022, jumlah ini akan meningkat menjadi US\$ 37,15 miliar, dengan Compound Annual Growth Rate (CAGR) 2017-2021 sebesar 18,8\%. Besarnya jumlah penduduk dan banyak orang Indonesia tidak pernah merasakan kehidupan finansial mereka dipengaruhi oleh organisasi keuangan menjadi tantangan tersendiri bagi startup fintech di tanah air. Dengan angka-angka ini, tidak mungkin untuk menyangkal bahwa perusahaan fintech membutuhkan undang-undang yang jelas dan spesifik.

Dewan Syariah Nasional Majelis Ulama Indonesia menetapkan fatwa No: 117/DSNMUI/II/2018 membahas layanan pembiayaan berbasis teknologi informasi syariah Hal ini dilakukan dalam rangka memperoleh akses uang yang lebih cepat, mudah, dan efisien. Fasilitas fintech syariah saat ini tengah menciptakan layanan pembiayaan berbasis teknologi bagi perusahaan mikro, kecil, dan menengah (UMKM). Masyarakat Indonesia membutuhkan penjelasan tentang norma dan batasan hukum yang mengatur layanan keuangan berbasis teknologi informasi syariah. Oleh karena itu, DSN-MUI mengeluarkan fatwa berdasarkan prinsip syariah untuk dijadikan pedoman dalam layanan keuangan berbasis teknologi informasi.

\section{Dinamika Fintech Syariah}

Perbedaan kontrak di perusahaan fintech yang sesuai syariah, sistem dual population yang dimiliki pengguna, menyulitkan pihak fintech syariah untuk menyaring data calon peminjam, dan data center yang harus ada di Indonesia menjadi salah satu kendala yang dihadapi oleh fintech syariah. fintech syariah. Oleh karena itu, solusinya adalah memberikan edukasi teknologi kepada masyarakat, memperluas jaringan internet, dan mempercepat transisi ke sistem kependudukan yang terintegrasi sehingga informasi yang dikumpulkan selama kegiatan penyaringan informasi untuk calon peminjam akurat. ${ }^{5}$

Selain itu, perusahaan fintech menghadapi persyaratan modal yang cukup tinggi saat mendaftar; perusahaan yang ingin mendaftar harus memiliki keuangan 1 miliar, dan ketika mendaftar ke OJK harus memiliki modal 2,5 miliar. Akibatnya, ini adalah masalah yang sekarang terjadi. Selain itu, seiring dengan meningkatnya kemajuan teknis di industri

\footnotetext{
${ }^{5}$ Dodi Yarli, “Analisis Akad Tijarah Pada Transaksi Fintech Syariah Dengan Pendekatan Maqhasid," YUDISIA: Jurnal Pemikiran Hukum Dan Hukum Islam 9, no. 2 (2018).
} 
pembiayaan, ketersediaan internet masih terbatas. Juga, ada kelangkaan sosialisasi bagi orangorang yang ingin menggunakan tekfin.

Solusinya adalah untuk membawa pendidikan ke daerah pedesaan di negara ini sehingga orang-orang di semua lapisan masyarakat dapat memperoleh manfaat dari kemudahan transaksi tekfin tanpa harus membayar materi pendidikan yang sesuai dengan syariah. Melihat pesatnya perkembangan fintech syariah sejak gerakan 212, semua orang bergembira, dan semua jenis syariah sedang ditunggu-tunggu di semua lapisan masyarakat..

Karena regulasi yang sekarang, fintech syariah menggunakannya sebagai pedoman dengan tetap berpegang pada standar fintech tradisional, maka perlu ada penyesuaian regulasi hukum. Sehingga legalitas fintech syariah tidak terpengaruh oleh aturan tertentu. Alhasil, regulasi tersebut harus memuat aturan khusus untuk fintech syariah. Selain itu, Mereka memberikan Edukasi Studi Fintech Syariah kepada semua lapisan masyarakat dalam upaya mengembangkan fintech syariah dalam kemitraan dengan anggota fintech lainnya. Perusahaan fintech harus memberikan perhatian ekstra pada maqashid syariah mereka untuk memastikan bahwa mereka patuh. Jangan sampai pendirian fintech syariah mengabaikan komponen syariah. Jadi, melihat kondisi fintech saat ini, solusinya tidak boleh dibiarkan begitu saja.

\section{Fintech Syariah Dalam Perspektif Hukum Islam}

Islam memuat sejumlah landasan hukum yang berfungsi untuk mengendalikan setiap aktivitas tatanan manusia. Salah satu dasar hukum Islam yang memberikan alasan tentang masalah yang diangkat di atas adalah larangan riba dan pembenaran jual beli. ${ }^{6}$

Dasar hukum fintech syariah berdasarkan hadits diantaranya yang diriwayatkan oleh Bukhori dari Ibnu Abbas, "Telah berata kepada kita sufyan dari 'Amr dari ibn Abās "Dahulu pasar 'ukaz, pasar mijannah, dan pasar dzu al-majāz merupakan pasar pada masa jahiliah, ketika pada masa islam orang-orang islam merasa berdosa untuk menghidupkan pasar-pasar tersebut kemudian turun ayat: tidak berdosa bagi kalian untuk mencari karunia dari Tuhan kamian-pada musim haji”. Berdasarkan hadits tersebut dapat dimaknai sistem perekonomian dan keuangan sebelum masa Islam terkadang diadopsi oleh Sistem ekonomi dan keuangan Islam didasarkan pada mengikuti peraturan hukum Islam.

\footnotetext{
${ }^{6}$ Q.S. Al-Baqarah : 275
} 
Fintech dalam Islam merupakan suatu pembahasan fikih kontemporer (Qadhaya Mu'ashirah). Yaitu suatu pembahasan dalam fikih yang tidak secara utuh ada hukumnya, dikarenakan pembahasannya baru muncul belakangan. Namun membutuhkan kaidah ushul fikih atau dasar/filosofi suatu hukum fikih. Jamal al-Banna ${ }^{7}$ dalam karyanya Nahwa Fiqh Jadid menyebutkan beberapa alasan akan kebutuhan Ijtihad. Diantaranya bahwa slogan ajtahidu ra`yii walaa `aalu, ijtihad dipahami ulama ushul fikih dengan bagian dari qiyas, sebagaimana dikatakan oleh imam Syafi'I bahwa ijtihad dan qiyas adalah dua nama yang berbeda dengan maksud yang sama. Bahkan jika dalam pemahaman ulama klasik tentang ijtihad dengan Istihsan, urf, masalih mursalah yang pada kesimpulannya adalah tentang maqasid syariah, maka ijtihad itu sendiri ialah tentang maqasid Syariah.

Merujuk kepada pendapat empat mazhab fikih (Mazhab Hanafi, Maliki, Syafi'I dan Hambali) tentang hukum fintech, tentu kita tidak menemukan hukumnya secara tekstual, akan tetapi terkait dengan prinsip dasar hukum tersebut dapat ditemukan. Prinsip-prinsipnya ditemukan dalam beberapa literature primer yang juga dijadikan sumber hukum dalam islam, seperti ilmu ushul fikih yang digagas oleh Imam Asy-Syathibi (w.1388 M.) dalam karyanya alMuwafaqat. ${ }^{8}$

Syariat islam memiliki tujuan khusus yang terangkum kepada tiga hal, yaitu pertama untuk tujuan primer, kedua sekunder, dan ketiga tersier. Tujuan primer maksudnya kebutuhan akan sesuatu yang harus ada untuk kemaslahatan agama dan dunia, yang jika tidak ada maka akan merusak tatanan kehidupan agama dan kehidupan di dunia, dan mengakibatkan penyesalan di akhirat. Hal ini bisa terpenuhi dengan rukun-rukunnya terpenuhi seluruhnya dan yang dengannya terhindar dari kehancuran dan kebinasaan. ${ }^{9}$

Berdasarkan pandangan imam Syathibi tersebut, penulis berpendapat bahwa jika suatu permasalahan saat ini yang belum diputuskan hukumnya dalam Al-Qur`an dan Hadis Nabi SAW, maka dapat menggunakan sumber hukum berikutnya yaitu ijma (konsensus ulama). Imam Syafi'I (w.820 M.) juga berpendapat tentang ijma (konsensus ulama) yang dapat digunakan sebagai sumber hukum dalam islam, ia berkomentar dalam karyanya Ar-Risalah: "Apa yang ulama islam diskusikan dan musyawarahkan dengan menisbatkan kepada Nabi SAW, maka yang demikian adalah benar." Namun karena umat islam tersebar dinegara yang

\footnotetext{
${ }^{7}$ Jamal Al-Banna, Nahwa Fiqh Jadid. (Kairo: Daar Kutub Arabia, 1995).

${ }^{8}$ Abu Ishaq bin Muhyiddin Asy-syathibiy, Al-Muwafaqaat. (Saudi Arabia: Daar Ibnul Jawjiz, 2008).

${ }^{9}$ Asy-syathibiy.
} 
berbeda-beda, maka berijma' secara fisik akan kurang efektif dan berijma' dalam satu pendapat akan lebih efektif. ${ }^{10}$

Fatwa Dewan Syariah Nasional-Majelis Ulama Indonesia (DSN-MUI) No.117/DSNMUI/II/2018 tentang Layanan Pembiayaan Berbasis Teknologi Informasi Berdasarkan Prinsip Syariah diterbitkan oleh Majelis Ulama Indonesia dan terdiri dari delapan bagian. : 1) aturan umum 2)aturan hokum 3)subjek hokum 4) aturan yang berkaitan dengan pedoman umum layanan pembiayaan berbasis teknologi informasi; 5) model layanan pembiayaan berbasis teknologi informasi; 6) ketentuan yang berkaitan dengan metode dan kontrak; 7) penyelesaian sengketa; 8) kondisi penutupanFatwa tersebut memperjelas ketentuan hukum dan kendala yang menjadi landasan syariah dari produk yang ditawarkan oleh start-up di Indonesia, menjawab kekhawatiran pelanggan atau pengguna operasi bisnis teknologi keuangan. Dengan demikian, fatwa tersebut dapat dianggap memberikan kepastian hukum dalam rangka meningkatkan kepercayaan masyarakat terhadap layanan pembiayaan berdasarkan prinsip syariah yang diberikan oleh start-up teknologi keuangan syariah, sehingga meningkatkan minat masyarakat untuk melakukan transaksi keuangan dengan memanfaatkan teknologi. ${ }^{11}$

\section{KESIMPULAN}

Dari Fatwa MUI Nomor: 117/DSN-MUI/II/2018 tentang Layanan Pembiayaan Berbasis Teknologi Informasi Berdasarkan Prinsip Syariah ini dan berdasarkan hasil penelitian dan pembahasan dapat ditarik kesimpulan yang dapat dijadikan dasar dalam menentukan hukum Fintech dalam islam. Fatwa tersebut merujuk kepada Al-Quran, Hadits, Kaidah Fikih dan Ijtihad ulama yang dapat dijadikan petunjuk bagi umat muslim dalam bermuamalah dengan fintech Syariah. Peneliti memiliki saran agar pihak-pihak terkait dapat memberikan tambahan literasi kepada masyarakat mengenai fintech Syariah melalui sosial media dengan menggunakan desain yang menarik agar lebih mudah dipahami.

\footnotetext{
${ }^{10}$ Muhammad bin Idris Asy-Syafi'I, Ar-Risalah (Beirut: Daar Kutub Ilmiyah, 1938).

${ }^{11}$ Rohmatun Nafiah and Ahmad Faih, "Analisis Transaksi Financial Technology (Fintech) Syariah Dalam

Perspektif Maqashid Syariah,” IQTISHADIA: Jurnal Ekonomi Dan Perbankan Syariah 6, no. 2 (2019): $167-75$.
} 


\section{DAFTAR PUSTAKA}

Al-Banna, Jamal. Nahwa Fiqh Jadid. Kairo: Daar Kutub Arabia, 1995.

Asy-Syafi'I, Muhammad bin Idris. Ar-Risalah. Beirut: Daar Kutub Ilmiyah, 1938.

Asy-syathibiy, Abu Ishaq bin Muhyiddin. Al-Muwafaqaat. Saudi Arabia: Daar Ibnul Jawjiz, 2008.

Aziz, Fathul Aminudin. "Menakar Kesyariahan Fintech Syariah Di Indonesia." Al-Manahij: Jurnal Kajian Hukum Islam 14, no. 1 (2020): 1-18.

Kasali, Renald. Discruption. Jakarta: Gramedia Pustaka Utama, 2017.

Nafiah, Rohmatun, and Ahmad Faih. "Analisis Transaksi Financial Technology (Fintech) Syariah Dalam Perspektif Maqashid Syariah." IQTISHADIA: Jurnal Ekonomi Dan Perbankan Syariah 6, no. 2 (2019): 167-75.

—. "Analisis Transaksi Financial Technology (Fintech) Syariah Dalam Perspektif Maqashid Syariah." IQTISHADIA: Jurnal Ekonomi Dan Perbankan Syariah 6, no. 2 (2019): $167-75$.

Shidik. Ushul Fiqh. Jakarta: PT. Intimedia Cipta Nusantara, 2016.

Yarli, Dodi. "Analisis Akad Tijarah Pada Transaksi Fintech Syariah Dengan Pendekatan Maqhasid.” YUDISIA: Jurnal Pemikiran Hukum Dan Hukum Islam 9, no. 2 (2018). 